\title{
BREWING THE 'PERFECT' STORY: \\ RE-ARTICULATING MARGINALIZED STORIES OF \\ FEMALE PLANTATION WORKERS \\ IN THE SRI LANKAN TEA INDUSTRY
}

\author{
by \\ Poornika Gunewardena
}

A research submitted to the University of Sri Jayewardenepura in partial fulfillment of the requirements for the Degree of Master of Business Administration 
The work described in this research was carried out by me under the supervision of Dr. Dhammika Jayawardena and a report on this has not been submitted in whole or in part to any university or any other institution for another Degree/ Diploma.

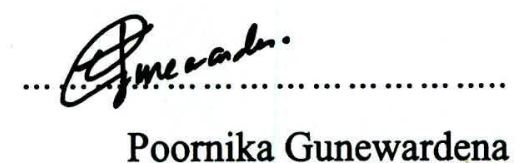


I certify that the above statement made by the candidate is true and that this research is suitable for submission to the University for the purpose of evaluation.

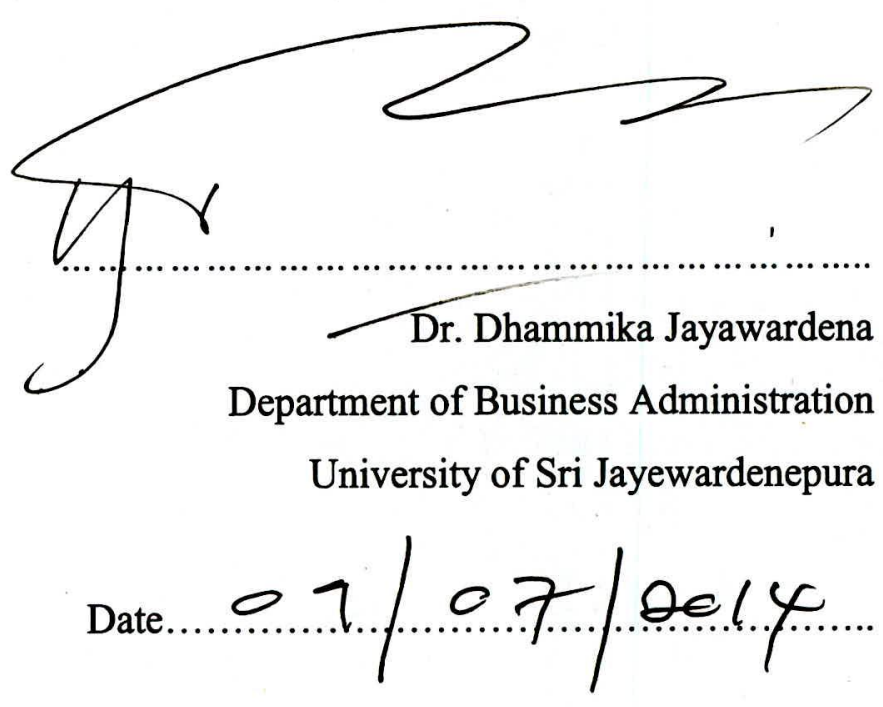




\section{TABLE OF CONTENTS}

Acknowledgements .vi

Abstract vii

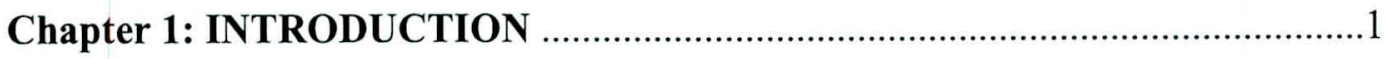

1.1 Context

1.1.1 Industry in focus........................................................

1.1.2 Organization in focus: Titanarum........................................

1.1.3 Collective story of the industry.........................................4

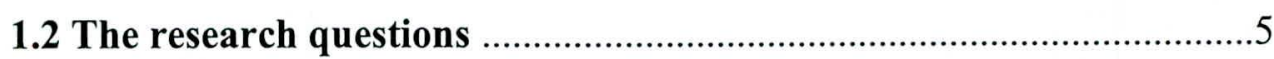

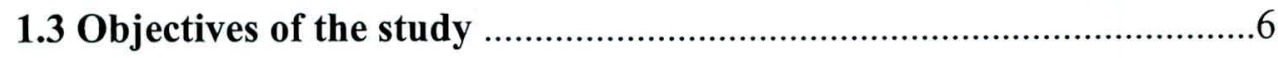

1.4 Importance of the study …...........................................................

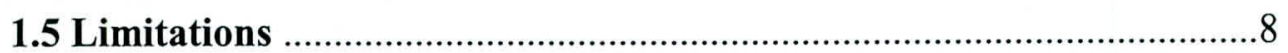

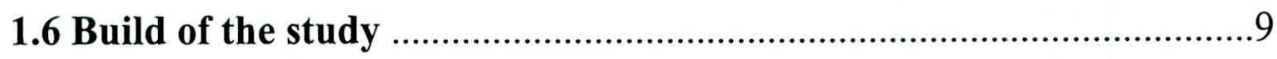

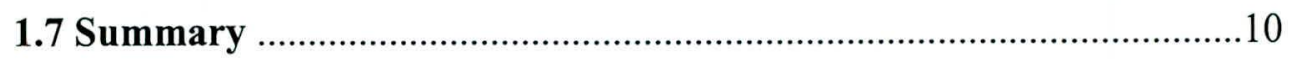

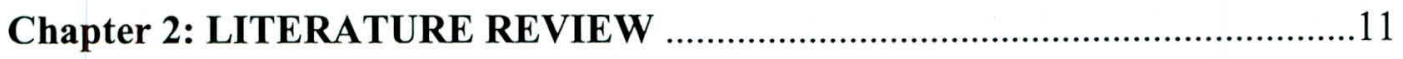

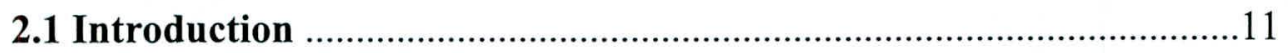

2.2 Narrative, story and their development ........................................12

2.2.1 Marginalization of folklore and re-emergence of story .......13

2.3 Organizational storytelling ........................................................... 16

2.3.1 Facts or fiction? ….........................................................16

2.3.2 Storytelling and sensemaking .........................................17 
2.4 Organizational narrative and the story of the other .23

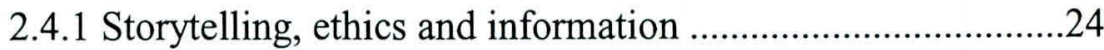

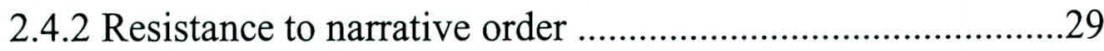

2.4.3 Organizational storytelling and society ............................29

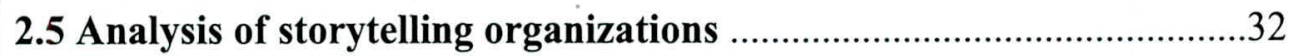

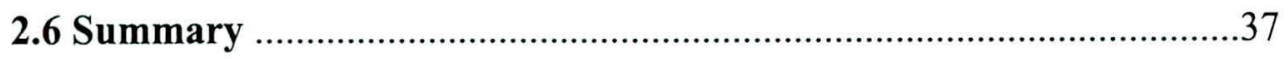

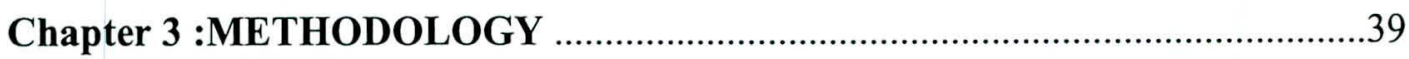

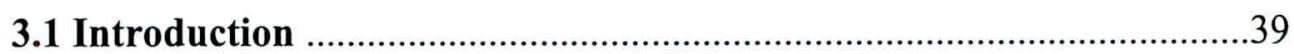

3.2 The telling in Titanarum's narrative ..............................................40

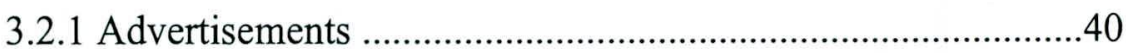

3.2.2 Product Packaging ............................................................. 42

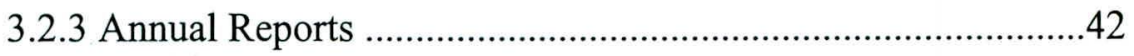

3.3 The telling of the Other's story ...........................................................4

3.3.1 Field work at the estate .....................................................45

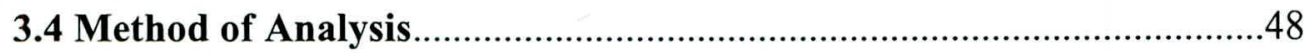

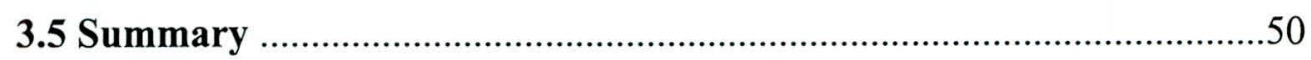

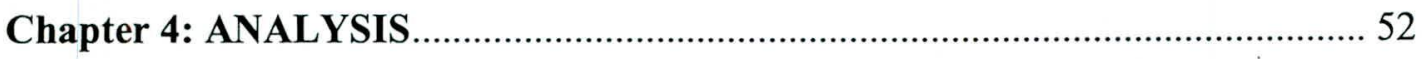

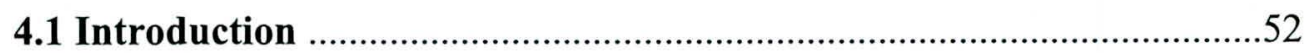

4.2 Deconstruction of Titanarum's narrative ...........................................53

4.2.1 Hierarchies and duality ...................................................53

4.2.1.1 Organization vs. the Other …..................................53

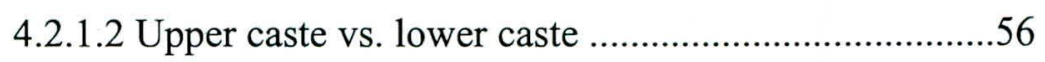

4.2.1.3 Hierarchies as a result of the system of governance....58 
4.2.2 Voices of the Other .59

4.2.2.1 Voices of the Other in Titanarum's telling .59

4.2.2.2 Voices of the Other as heard at the estate 61

i. Voice of the illiterate .61

ii. Voice of the domestically abused............................63

iii. Voice of members of different castes.....................65

iv Voice of the uninformed..........................................65

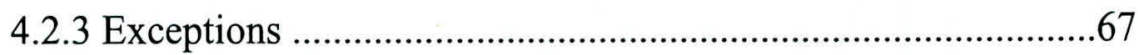

4.2.4 Denying the plot ................................................................

4.2.5 Filling in the gaps.............................................................. 73

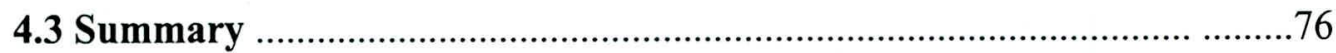

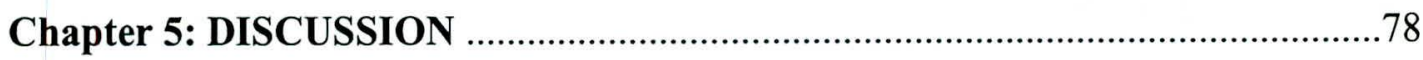

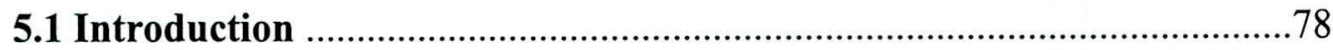

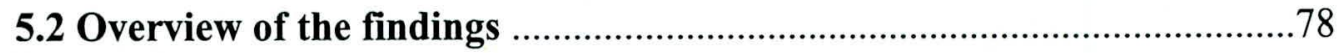

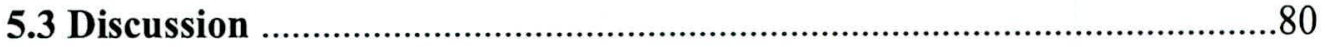

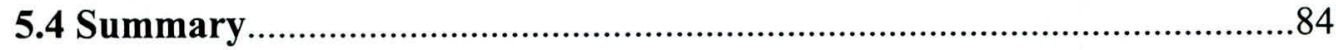

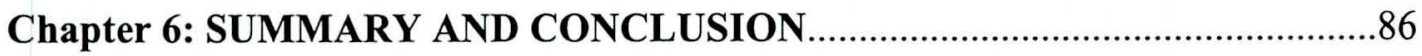

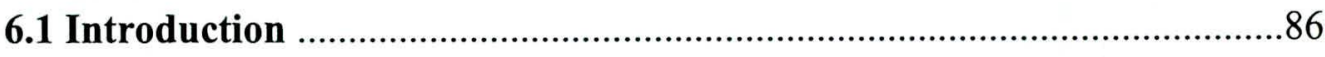

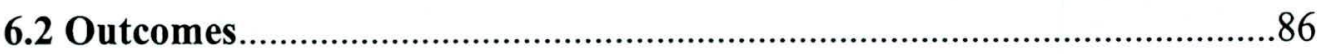

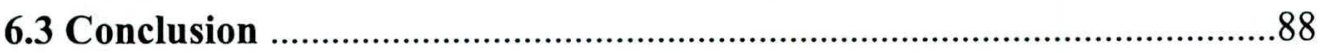

6.4 Recommendation for future developments.........................................90 
Appendix A. Advertisements on T-Gold.....................................................101

A.1.Advertisement 1.................................................................. 101

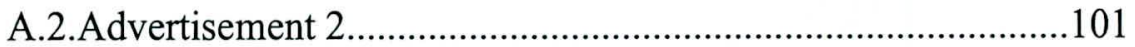

A.3.Advertisement 3 ..........................................................102

A.4.Advertisement 4 .................................................................103

Appendix B. Advertisements on T-Silver.....................................................104

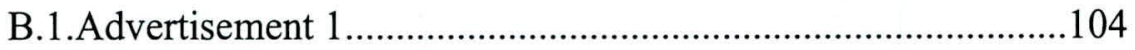

B.2. Advertisement 2............................................................. 104

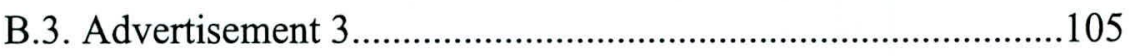

B.4. Advertisement 4........................................................105

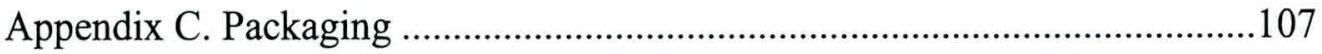

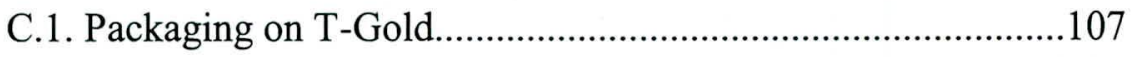

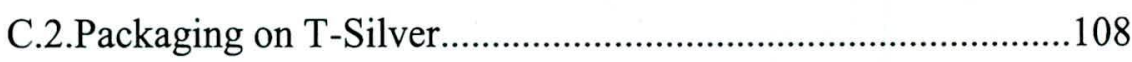

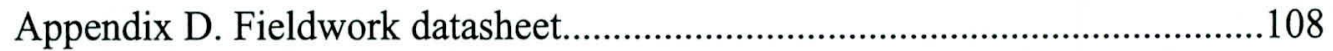

Appendix E. OCCURRENCE OF SELECTED WORDS IN THE

ANNUAL REPORTS 


\section{List of figures}

Figure i. Method of Story-Deconstruction …….....................................35

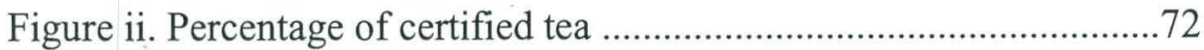




\section{ACKNOWLEDGEMENTS}

My sincere gratitude goes out to my supervisor Dr. Dhammika Jayawardena for his guidance and invaluable advice without which the successful completion of this study would not have been a possibility.

I would also like to extend my appreciation to Mr. D. W. S. Narangoda, Director General of Sri Lanka Tea Board for granting permission to carry out field work in Sri Lankan tea estates. I'm also thankful to Dr. Gerry Jayawardena, Chairman of the Tea Research Institute of Sri Lanka for the assistance provided towards this study.

Last but not least, I would like to thank my family and loved ones for all the support extended towards this research. 


\title{
Brewing the 'perfect' story: \\ Re-articulating marginalized stories \\ of female plantation workers in the Sri Lankan tea industry \\ by
}

\section{Poornika Gunewardena}

\begin{abstract}
This research analyses the Sri Lankan tea industry in the context of organizational storytelling. It takes into consideration the 'heard' voices of Titanarum, a leading tea manufacturing company, and the 'unheard' stories of its stakeholders. While the organizational story is often accessible to society and widely heard, there exists another set of stories arising from the workers of estates that supply tea to the island's tea auction. These voices are often unheard and inaccessible to society. Thus the study focuses on these marginalized voices which hoard vital stories necessary for the creating a comprehensive industrial narration to society. The study encompassed a qualitative research methodology incorporating the method of 'deconstruction' which enabled the creation of a 'restory'. Devoid of any form of dualities and hierarchies, the 'restory' avoided the centering on the rather 'optimistic' narration of Titanarum or the 'pessimistic' story as put forth by the tea pickers. Aforesaid decentering facilitated the re-articulation of marginalized female worker story as a part of a collective narration instead of a story told in isolation. In conclusion, the research substantiated that the female plantation worker story was one about a group in isolation; sidelined by illiteracy, caste differences, gender roles, lack of general knowledge, traditional systems of ruling and inherent feelings of self-subservient conduct.
\end{abstract}




\section{Chapter 1}

\section{INTRODUCTION}

Alan Kay, the former vice president of Walt Disney once said: "Why was Solomon recognized as the wisest man in the world? Because he knew more stories than anyone else. Scratch the surface in a typical boardroom and we're all just cavemen with briefcases, hungry for a wise person to tell us stories" (McLellan, 2006:20). Indeed, the art of storytelling has seen a revival of interest among today's organizational leaders, who do not view stories as mere narrations used to convey events but as a currency in making sense of the said events (Gephart, 1991:37). As the medium of internal and external communication, these managerial stories are vital both to the structuring of the system of information and the subsequent creation of the organizational identity. When these narrations, originating from an organization penetrate into society they become part of a cycle of stories composed of varied tales by different narrators such as suppliers, distributers, customers, activists, government and non-government organizations and other numerous institutions. A system of stories which provides a "voice" to all these possible narrations from all of its participant storytellers can be deemed as a comprehensive source of information as it provides access to all probable perspectives with regard to an industry. The possible marginalization of selected voices would in turn render the cycle of stories as rather inaccurate and subsequently questions its suitability as a source of information to society.

In this context, this research analyses Sri Lankan tea sector by examining if the female plantation worker voices are facilitated with a podium for expression beyond the boundaries of the estate premises, thereby assisting the 
unhindered transportation of their narrations to society. For the purpose of this study, I selected the leader in both local and global tea supply and distribution: an organization which was reluctant in getting directly involved in this study as they thought its content was rather 'sensitive' and could be harmful to their brand images; thus its actual name is not used and when needed the said organization is identified as Titanarum throughout this research.

\subsection{Context}

\subsubsection{Industry in focus}

Tea, rubber and coconut: the three crops which have dominated the Sri Lankan plantation sector for centuries by being the major contributors to the country's gross domestic product. Out of the three, tea comes forth as the dominant crop not only because the island is the fourth largest producer of tea in the world but also because it is revered for the high quality of its tea which has long been unmatched by its competitors. Accounting for $2 \%$ of the island's GDP with an annual contribution of $\$ 700$ million (National Accounts of Sri Lanka, 2012) the island exports most of its produce and is the second largest exporter of tea in the world.

As widely known, tea was introduced to the island by the British. The first crop to receive government sponsorship was cinnamon, and that was under the Dutch rule. Cinnamon continued to be a crop of importance even under the British until the recession in 1830 which had dire effects on England's economy and negatively impacted the cinnamon plantations in Ceylon and elsewhere in the world. As a result, the British turned their gaze at coffee. However 'coffee leaf disease' in 1869 ensured the decline of coffee production in the ensuing years (Steiman, 2013). By that time, 
most of the plantations in the island were prepared for coffee and subsequent attempts at introducing cocoa and cinchona proved to be ineffective. As a result, in 1870, planters in Ceylon turned towards tea (Herath, 2004): a move which has continued to result in financial profits even centuries after its introduction.

The growth of tea sector demanded more labor: an employment opportunity which was not eagerly grabbed by the majority Sinhalese and thus resulted in the arrival of Indian Tamils who were specifically brought down to the island to work in the tea estates (De Silva,1981). At present, the tea sector directly or indirectly employs over one million people, which is significant for an island with a population of twenty million. And to this day a significant portion of the tea picking activity in estates in Hill country is carried out by the descendants of those Indian Tamils who were brought to the island centuries ago.

\subsubsection{Organization in focus: Titanarum}

Sri Lankan tea industry is significantly controlled by private organizations where some maintain their own estates while others choose to buy tea from the Colombo Tea auction. Due to time limitations, I was required to select one out of many companies as the organization in focus: the stories of which were adopted as the narrations of the industry to the wider society. The choice of Titanarum as the storytelling organization in my study was fuelled by the fact that it is the leader in both local and global context with regard to tea production and sales (Tradeforum.org, 2014). Simply put, Titanarum is the world's biggest tea company!

With more than 400 brands under its belt and with 2 billion people using its products on any given day, Titanarum is pretty much the undisputed king of 
consumer products. 14 brands in the organization's portfolio boast of sales of more than $€ 1$ billion a year. As informed on Titanarum's official site, the firm's products are sold in more than 190 countries resulting in sales of $€ 51$ billion in 2012 . In the foregone year, the organization managed to add nearly $€ 5$ billion of turnover, pushing through the $€ 50$ billion mark in the process. What is fascinating is not just the financial figures but also the impact Titanarum has on its significant labor force with more than 173,000 people working for the organization in addition to its 252 manufacturing sites across the world.

In the local context, Titanarum's Sri Lankan office manages functions such as production, sales, distribution etc. of its products. It is interesting to note that the organization is not registered in the Sri Lankan stock exchange and thus is not bound by law to publish any details pertaining to its financial, shareholder or profit positioning. With regard to this study, I focused on Titanarum's tea brands, out of which the world's most reputed tea brand, T-Gold (name changed due to organization's concerns) is one of its 'billion-euro' brands generating annual sales of billion euros or more. It is interesting to note that while Titanarum maintains its own tea estates in countries like Kenya and India, the organization's main source of tea in the island is the Colombo tea auction in which it is the second largest buyer.

\subsubsection{Collective story of the industry}

In isolation, the organizational story as narrated by Titanarum is often a story about the 'bright and happy' side of the industry, carefully knitted in order to influence its customers into buying a product. The plantation worker story in contrast is a rather 'dark' telling which often captures all that is bad in an industry. Hence, on 
one side, one of the most successful and famed entrepreneurs ever, asserting the positive aspects of its brands; on the other side a group of women who are seldom given a voice. The two protagonists standing in irreconcilable opposition, attempt to refute the claims of the other in order to justify their beliefs and narrations. Hence, when analysed individually, the two stories would be centred either on the 'darker' narration of the female workers or the 'sunny and happy' telling of the organization. In order to avoid such centralization the two narrations were amalgamated and explored as a collective story instead of isolated narrations. This was achieved by adopting Boje \& Dennehy's (1993) method of deconstruction which enabled the recognition of dualities, hierarchies, different voices, exceptions and gaps. Such identification aided the review of the resultant 'restory' without being absorbed and influenced by the dualities, hierarchies and narrative control and thus it was possible to gain a more 'balanced' articulation of female worker narrations.

\subsection{The research questions}

The heart of the study lies in determining if the female plantation worker voice is marginalized. It also calls for the identification of reasons for such omission of worker stories from the narrations to society. In such context, this research calls for the exploration of answers to the below mentioned questions:

- Are female plantation worker stories marginalized?

- If yes, what is the reason for such marginalization?

These research questions however, give way to a series of underlying sub questions such as, 